\title{
Developing an Automated City of Whittlesea Urban Tree Canopy Inventory Using Airborne LiDAR and Aerial Imagery
}

\author{
Sultana Nasrin Baby' ${ }^{1}$ Bozena Wojcik², Adrian Murone ${ }^{3}$, Linda Martin-Chew ${ }^{4}$, Nadhir Al-Ansari ${ }^{*}$ \\ ${ }^{1}$ Royal Melbourne Institute of Technology, RMIT University, Melbourne, Australia \\ ${ }^{2}$ Senior GIS Officer at City of Whittlesea, Melbourne, Australia \\ ${ }^{3}$ Arborist and Aspiring Urban Forester, Melbourne, Australia \\ ${ }^{4}$ Consultant/Director Plan-It Rural PL and Senior Strategic Policy Planner at City of Whittlesea, Melbourne, Australia \\ ${ }^{5}$ Lulea University of Technology, Lulea, Sweden \\ Email: Nasrin.Sultana@whittlesea.vic.gov.au,info@whittlesea.vic.gov.au,info@whittlesea.vic.gov.au,info@whittlesea.vic.gov.au, \\ *nadhir.alansari@ltu.se
}

How to cite this paper: Baby, S.N., Wojcik, B., Murone, A., Martin-Chew, L. and Al-Ansari, N. (2019) Developing an Automated City of Whittlesea Urban Tree Canopy Inventory Using Airborne LiDAR and Aerial Imagery. Engineering, 11, 828-840. https://doi.org/10.4236/eng.2019.1112057

Received: December 11, 2019

Accepted: December 21, 2019

Published: December 24, 2019

Copyright $\odot 2019$ by author(s) and Scientific Research Publishing Inc. This work is licensed under the Creative Commons Attribution International License (CC BY 4.0).

http://creativecommons.org/licenses/by/4.0/

\section{(c) (i) Open Access}

\begin{abstract}
The City of Whittlesea is in Melbourne's north and is one of the largest municipalities in metropolitan Melbourne. The council GIS team using current aerial photos from 2017 and LiDAR ("LiDAR" stands for Light Detection and Ranging) point clouds 2009 products to identify trends in urban tree canopy cover in the established suburbs of the municipality between 2009 and 2017. The tree canopy coverage was calculated for residential properties, road reservations, public land and park sites within urban parts of Bundoora, Epping, Lalor, Mill Park, Thomastown, and South Morang. From the total project area of approximately 3499 hectares a test site was selected based on an extension of one of the LIDAR data tiles (e325n5828). This project investigates only 6 meters and higher tree canopy cover within the project area. The objectives of the project were to establish a methodology to calculate the urban tree canopy coverage from LiDAR 2009 data, that can be replicated in future calculations. The calculated urban tree canopy coverage from LiDAR 2009 data is $9 \%$, compared to $8 \%$ coverage in 2017 , based on aerial photography. This estimate was compared to similar Local Governance Areas that range from $12 \%$ to $40 \%$. A key to planning and managing urban tree canopy is first to understand the quantity, quality, tree density and distribution of the resource across the landscape. Tree inventories and urban tree canopy analyses comprise an assortment of tools, technologies, and procedures that help us understand the structure and function of our urban tree canopy. The data and information gleaned from urban tree canopy assessments enable resource professionals and policymakers to make informed decisions about ordinances, housing di-
\end{abstract}


versity strategy, and budgeting, future tree planting programs and reduce urban heat islands.

\section{Keywords}

LiDAR, GIS, Arial Photo, Canopy, Housing Diversity, LGA

\section{Introduction}

Canopy tree cover is the aboveground portion of plant or crop growing in a particular area. This Project was developed to support the Stage 2 implementation of the Council's Housing Diversity Strategy 2013-2033 (HDS). The Project sought to identify trends for urban tree canopy cover in the established suburbs of the municipality between 2009 and 2017. The expectation was that urban tree canopy cover data had reduced over time, with probable causes being infill development, the millennium drought, and the natural senescence and renewal of street trees [1]. A downward trend in urban tree canopy cover, if identified, would support changes to planning controls to increase private open space and landscaping, particularly canopy trees, in new residential development.

The HDS 2013-2033 states that the dominance of hard surfaces, building bulk, and lack of access to attractive outdoor spaces, has been a key design concern with residential development in the City of Whittlesea [2]. These extensive hard surfaces, un-shaded by vegetation, absorb the sun's heat and lead to metropolitan temperatures that can be seven degrees Celsius higher than those in surrounding rural areas [3].

The Project identified a critical decline in urban tree canopy cover in areas of highest infill development activity, from an already low base. The project also highlighted serious inequities in overall urban tree canopy cover when compared to other middle ring suburbs of Melbourne. Total urban tree canopy cover for the established areas of the municipality in 2017 was $8 \%$ compared to canopy cover measurements in similar LGAs (new born plants) that range from $12 \%$ to $40 \%$.

There is a need to increase and maintain urban tree canopy cover going forward, from the perspective of amenity, energy efficiency and urban heat island effects. Whilst Council has an ongoing role in managing and increasing tree cover in public parks and residential streets, trees in the private realm are also important contributors to the urban forest [4]. The data from this project will be used to support changes to planning controls for residential housing to ensure canopy trees are provided as part of new development in private residential land.

The recommended planning scheme changes include a local planning policy addressing housing typology and design, and changes to zone schedules to ensure canopy trees are part of the development design, and that residents have access to useable private open space [5]. Support for canopy trees in local planning policy and variations to the ResCode standards for secluded private open 
space and rear setbacks will increase the area available for tree provision. Variations to ResCode standards to ensure the housing design allows for canopy trees has a compounding impact on the design of development: it affects site permeability, shade, building design and delivery of ground level open space [6].

\section{Background}

The HDS (key design principles in Environments for people) sought to establish a preferred character in the established suburbs using key design principles for new residential development, including increased landscaping and particularly the provision of canopy trees in front and rear setbacks. Other elements of the key design principles seek to improve the internal and external amenity of housing in the established suburbs, including access to secluded private open space and generous side and rear setbacks.

The HDS key design principles, if taken into account in the design of the development, should be directing an overall increase in the quality and quantity of landscaping. However, the provision of canopy trees is an important spatial requirement in development design that has not been well executed to date. This has been partly attributed to the incomplete implementation of the HDS in 2015 when new residential zones were approved by the Minister for Planning.

The HDS is a reference document in the Whittlesea Planning Scheme, from which policy elements were introduced to Clause 21 (Municipal Strategic Statement) in 2015. Despite this existing planning scheme support, VCAT reviews of development applications have not applied weight to the canopy tree requirement due to the perception that there should be more local content in the planning scheme to support canopy trees.

As such, an important objective of the Stage 2 HDS implementation in 2018 will be to introduce planning controls that provide more certainty with respect to the delivery of canopy trees, with an overall improvement in the landscaping response. Although the canopy tree requirement is part of Council's adopted housing policy, there was concern that the evidentiary support for its inclusion was not clearly expressed in the HDS. As such, the Urban Tree Canopy Cover Project was developed to provide locally specific evidence that intervention is required if canopy trees are to be delivered in both the public and private realm.

\section{Methodology}

The opportunity to undertake the project arose due to the availability of LiDAR data from 2009 which could be used to "benchmark" the urban tree canopy cover from that period. The technology uses pulsed laser light to measure the distance to a target on the ground, in this case measuring the ratio of vegetation to ground and buildings.

LiDAR imaging is very expensive, and 2017 LiDAR data was unfortunately not available. Instead, a project methodology was developed by GIS officers in Council to build the 2017 data using aerial photography. The project methodology is detailed in the following sections. 


\subsection{Vegetation Parameters}

The data from the Project is expressed as "overall canopy tree cover" which is a measure of the physical coverage of the tree canopy cover over the land [7].

It is a measure that can be used to assess community resilience to climate change. For example, a recent study on the urban heat island effect in Melbourne recommends that one of the most cost efficient and effective climate change mitigation strategies is to ensure a minimum canopy cover of $30 \%$ within the municipality [7].

An early consideration in the project design was how to define a "tree", to separate this form of vegetation from shrubs and groundcover in the data analysis. The figure of six metres and above was selected for the following reasons:

- 6 - 8 metres are defined as a "small tree" in Clause 58.03-5 (Apartment Developments: Site layout-Landscaping objectives) of the Whittlesea Planning Scheme. This is the only part of the planning scheme which currently defines a tree by size.

- When defining a tree, the term usually applies to plants at least six metres high at maturity. This would appear to be the minimum to achieve the "shading intent" of urban tree canopy coverage.

\subsection{Study Area}

The 2009 LiDAR data was available within a spatial arrangement of "tiles" which could be overlaid within the boundary of the established suburbs to create the study area (refer to Figure 1). Epping Central was excluded (as it is subject to the Epping Central Structure Plan and the Activity Centre Zone), as was any tile that was lower in residential content (such as the areas with a proportion of industrial development south of the Metropolitan Ring Road).

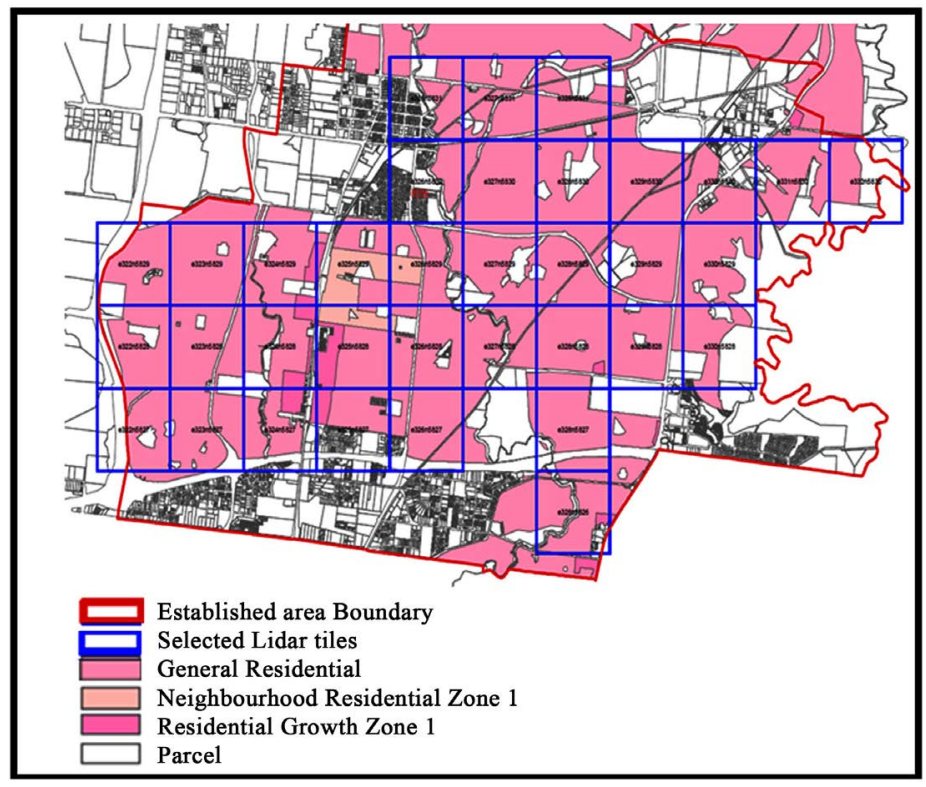

Figure 1. City of Whittlesea "established area" boundary and LiDAR tiles determined the study area. 


\subsection{Data Capture Methods}

Data capturing method is the method is the method of collecting information and then changing it into a form that can be read and used by a computer. The measurement of urban tree canopy cover is a challenging exercise because the remote sensing technology does not distinguish between trees and buildings, so both would be captured above the selected elevation of six meters.

A literature review was undertaken, followed by trials with various methods for measuring tree canopy cover using LiDAR plus aerial imaging. The intent was that a consistent methodology is developed to continue measuring urban tree canopy cover in the future.

ArcGIS image analysis delivered the most efficient methodology in terms of time and accuracy. Future Manipulation Engine (FME) Workbench was then used to calculate areas of total tree canopy cover (crown), dividing the proportions of canopy cover per suburb within the following categories:

- Overall suburb coverage;

- Within residential properties;

- Within council reserves;

- Within public land; and

- Within road reservations.

Classification and with tree crown delineation-using watershed ss. The results showed less than $1 \%$ departure from the previous data, indicating that the Project has provided reliable estimates of tree canopy coverage across the study period.

LiDAR data for 2017 is being purchased later in 2018, and the methodology can be used again, to test the Project results for accuracy.

\section{Results and Discussion}

The results provided comparative tree canopy cover percentages for the separate location categories in 2009 and 2017 (refer Figure 2).

The benchmarking at 2009 showed that the established areas of the municipality had a relatively low overall tree canopy coverage of $9 \%$, which dropped to $8 \%$ over the study period.

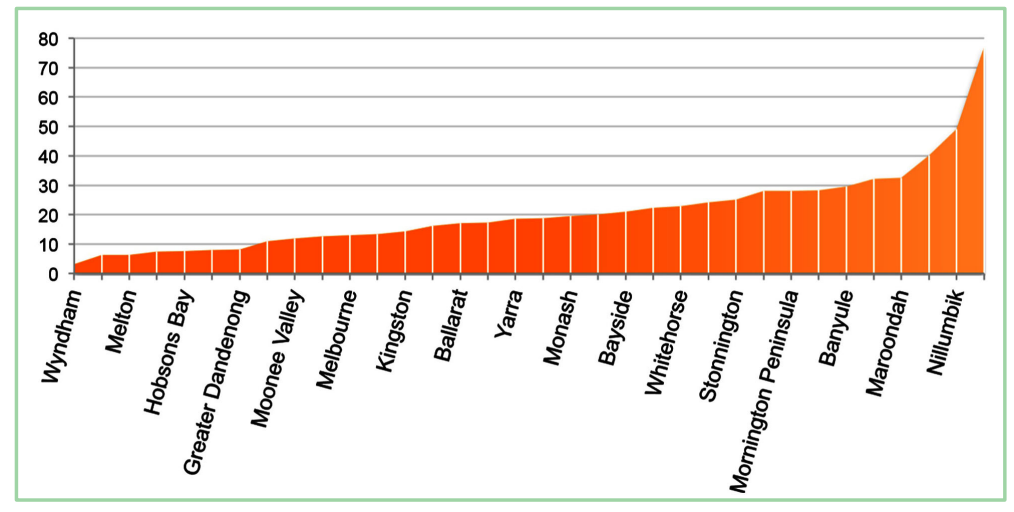

Figure 2. Canopy cover (\%) for selected Victorian Local Government Areas [9]. 
This has highlighted inequities for the established areas of City of Whittlesea when compared to urban tree canopy cover measurements in other middle-ring Victorian LGAs [8]:

- Moonee Valley $12 \%$;

- Monash 20\%;

- Whitehorse $24 \%$;

- Banyule 33\%;

- Maroondah $40 \%$.

For Victoria, the i-Tree assessment included 34 LGAs, which account for $77 \%$ of the Victorian population (ABS, 2012), in the Greater Melbourne Region. Tree cover ranged from $77 \%$ in the Yarra Ranges to 3\% in the City of Wyndham (Figure 2).

The geographic distribution of tree cover, with Manningham, Nilumbik and the Yarra Ranges in the northeast showing tree cover over $40 \%$. The Yarra Ranges LGA contains a large portion of National Park, with a tree cover of 1906 $\mathrm{km}^{2}$. In contrast to the large areas of tree cover presented in the regions, 19 of the LGAs in the Greater Metropolitan Area exhibit tree cover less than 20\%, of which 7 LGAs have a tree cover of less than 10\%. Wyndham, Melton and Hume, which present less than $10 \%$ tree cover, have grass-bare ground cover of over $77 \%$.

For the most part, the LGAs with less than $20 \%$ tree cover are in the inner city and western regions of the Greater Melbourne Area. City of Port Philip, City of Yarra and City of Melbourne present the greatest proportion of hard surface and relatively lower proportions of grass-bare ground.

Whilst the decrease in canopy cover over time across the entire study area was not dramatic, the difference was much more pronounced in suburbs with the highest multi-dwelling building activity such as Bundoora, Lalor and Thomastown.

Within Lalor and Thomastown, multi-dwelling activity was particularly high in the area bounded by The Boulevard to the south, Childs Road to the north, Darebin Drive to the east and High Street to the west. Losses in these two suburbs, and in the area of particularly high development activity, are shown in $\mathrm{Ta}$ ble 1 .

Between 2009 and 2017, the "high development area" experienced a loss of $23.45 \%$ canopy cover (Lalor) and $25.25 \%$ (Thomastown). To put this further into perspective, Lalor and Thomastown represent a combined $45 \%$ of the study area but accommodate less than $2 \%$ of the overall urban tree canopy cover.

Table 1 also shows relatively high tree canopy losses in public land and road reservations, compared to that lost in Council land (parks and reserves). The percentage of tree loss on public land in Lalor and Thomastown was $16.02 \%$. This is the result of the rail duplication to Epping, with significant tree losses occurring in the rail reservation on the western edge of the high development area. 
Table 1. Tree canopy loss in the areas of highest multi-dwelling development activity [10].

\begin{tabular}{|c|c|c|c|c|c|}
\hline Suburb & $\begin{array}{l}\% \\
\text { Study Area }\end{array}$ & $\begin{array}{l}\% \text { coverage } \\
2009\end{array}$ & $\begin{array}{l}\text { \% coverage } \\
2017\end{array}$ & $\begin{array}{l}\% \\
\text { Difference }\end{array}$ & \\
\hline Bundoora & 6.96 & 8.94 & 8.47 & -0.76 & \\
\hline Lalor & 20.64 & 5.15 & 4.53 & -0.62 & \\
\hline Thomastown & 23.21 & 4.71 & 4.35 & -0.36 & \\
\hline $\begin{array}{l}\text { Highest infill } \\
\text { development activity } \\
\text { bounded by the } \\
\text { Boulevard, Childs } \\
\text { Road, Darebin Drive } \\
\text { and High Street }\end{array}$ & $\mathrm{N} / \mathrm{A}$ & $\begin{array}{l}\text { Residential } \\
\text { land \% tree } \\
\text { coverage } \\
2009-2017\end{array}$ & $\begin{array}{l}\text { Council } \\
\text { Land \% tree } \\
\text { coverage } \\
2009-2017\end{array}$ & $\begin{array}{l}\text { Public Land \% } \\
\text { tree coverage } \\
2009-2017\end{array}$ & $\begin{array}{l}\text { Road } \\
\text { reservations \% } \\
\text { tree coverage } \\
2009-2017\end{array}$ \\
\hline Lalor/Thomastown & & $-23.24 \%$ & $-3.84 \%$ & $-16.02 \%^{\star}$ & $-17.08 \%$ \\
\hline
\end{tabular}

Identifying the reasons for tree canopy loss in road reservations $(-17.08 \%$ in the high development area) is not straightforward. There is ongoing street tree renewal programmed in these areas due to natural senescence, and the millennium drought has impacted the health of trees in public places (although the losses in Council land may be a more realistic measure of this effect). However, there is no doubt that infill development also leads to the removal of street trees due to driveway duplication/relocation, and the relocation of utility services as part of development.

\subsection{Visual Tools}

The project provided an opportunity to obtain visual representations of tree canopy cover decline and the way that "backyard spaces" have diminished over the study period. Figure 3 shows LiDAR-derived tree polygons (?) from 2009, overlaid on a 2017 aerial photograph of a block with high development activity within the suburb of Lalor. Figure 4 shows the same block with the LiDAR representation of 2009 trees (mostly now lost) shown in elevation.

The visual representations make it clear that infill development has diminished the amount of private open space available to residents, and that canopy tree losses as a result of development are unlikely to be replaced due to the lack of suitable growing space (refer Figures 5(a)-(c)).

Figures 5(a)-(c): Aerial photography from a block in Thomastown in 2009, 2017 and a visual representation of the 2025 projection assuming development occurs at the same rate and the housing typology does not change. It demonstrates the effect that infill development has on landscaping opportunities and private open space.

\subsection{Recommendations for Planning Scheme Changes}

The HDS highlighted key design concerns with residential development in City of Whittlesea that relate to the dominance of hard surfaces and building bulk, and lack of access to attractive outdoor spaces [10]. These hard surfaces, un- 
shaded by vegetation, absorb the sun's heat and lead to metropolitan temperatures that can be seven degrees Celsius higher than those in surrounding rural areas.

This is not to ignore the amenity value of trees, which is likely to have also been an important factor in their inclusion in the HDS key design principles. However, the "amenity" argument has not prevailed in VCAT reviews of Council decisions, and the trees are generally not delivered in newly approved development.

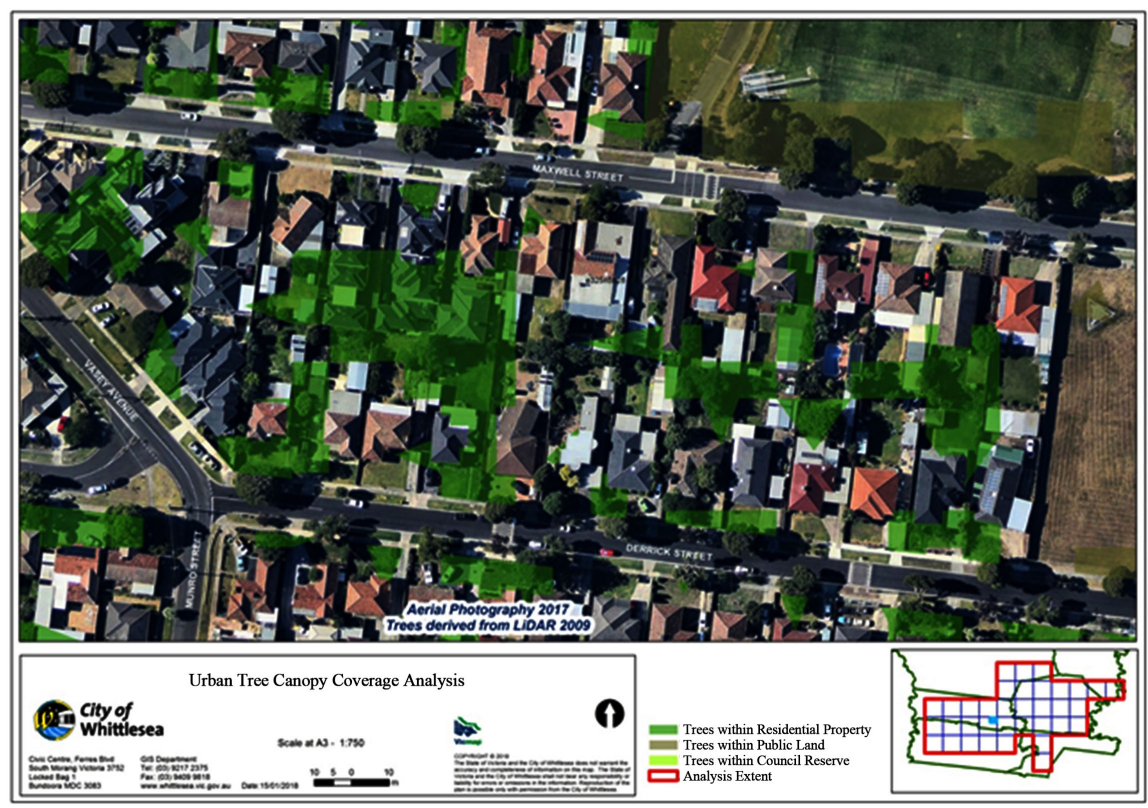

Figure 3. Aerial Photography 2017 with trees derived from LiDAR 2009.
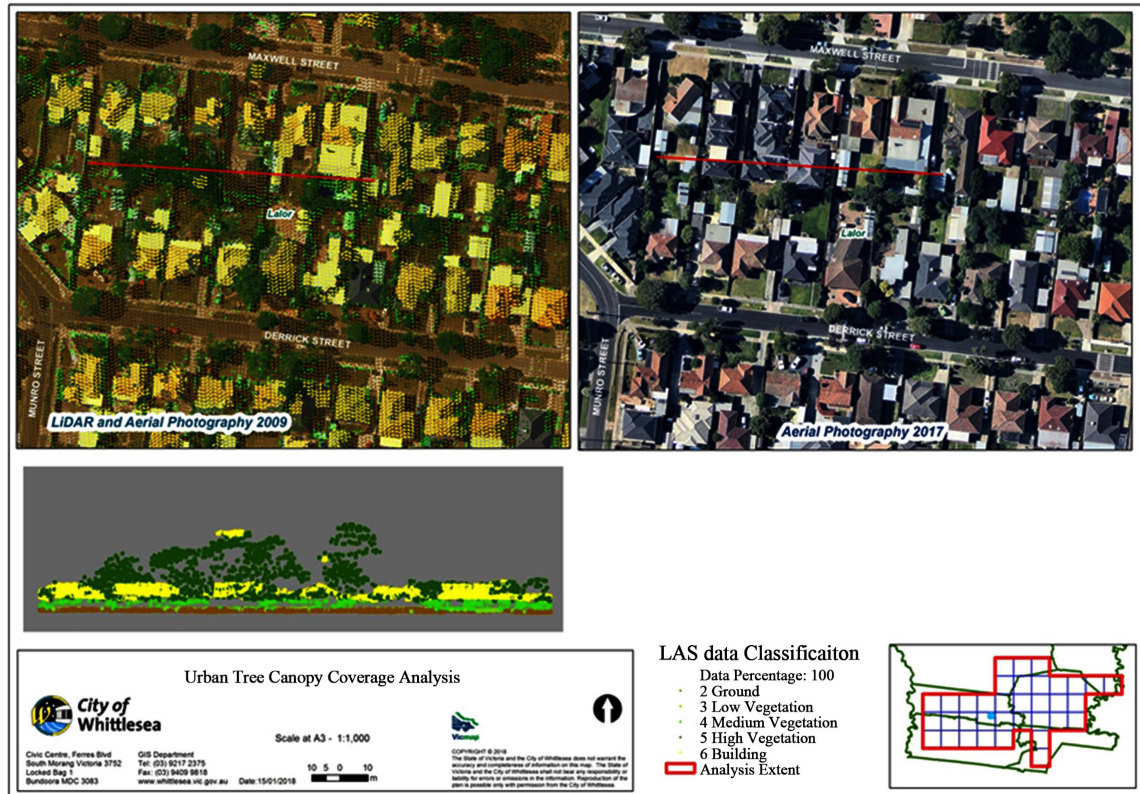

Figure 4. LiDAR representation of 2009 trees shown in elevation (same block as Figure 3)-arger trees now lost. 


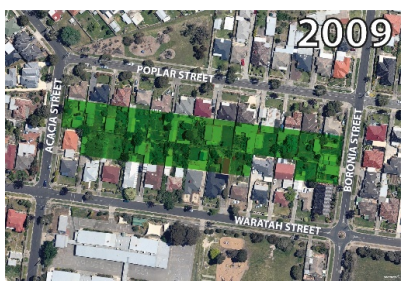

(a)

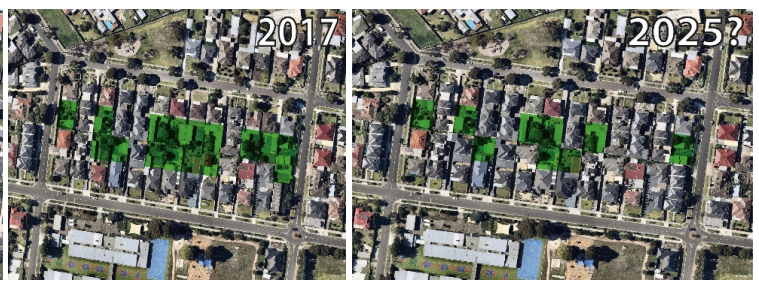

(b) (c)

Figures 5. (a), (b), (c): Aerial photography from a block in Thomastown in 2009, 2017 and a visual representation of the 2025 projection.

In contrast to this, monetary values have been applied to the environmental benefits of tree populations and to the health impacts of urban heat islands. Increased tree canopy cover can reduce the local impact of heat in our residential environments, and increase carbon sequestration to contribute to the reduction of carbon emissions. Urban forests assist with the management of storm water, improve air quality, provide habitat for wildlife and contribute to landscape values and aesthetics [11].

The Resilient Melbourne Strategy notes that extending and linking urban greening, reforestation and initiatives to introduce nature across Melbourne will improve wellbeing and reduce exposure to hazards such as heat waves and flooding. These phenomena will become widespread and will disproportionately affect vulnerable community members such as older residents, those in poor health and the financially disadvantaged. A primary community resilience objective from the Resilient Melbourne Strategy is to enable strong natural assets and ecosystems alongside a growing population [12].

Whilst Council has an ongoing role in managing and increasing tree cover in public parks and residential streets, trees in the private realm are also important contributors to the urban forest [13]. One indication of the increasing awareness of this issue was the recent introduction of a "deep soil and canopy tree objective" as part of the Better Apartment Design Standards in the Victorian Planning Provisions:

To promote climate responsive landscape design and water management in developments to support thermal comfort and reduce the urban heat island effect.

The relevant provision seeks a minimum number of canopy trees within the site, determined by the site area.

As such, data from this project will be used to support changes to planning controls for residential housing to ensure canopy trees are provided as part of new development in private residential land $\mathrm{m}$ (Figure 6 and Figure 7).

According to the Institute for Sustainable Futures (ISF), the City of Wyndham has the greatest potential for increased tree canopy coverage due to its large expanses of grass-bare ground cover. In their 2015 report, the ISF determined that approximately $3.1 \%$ of the area of Wyndham was covered by tree canopy. Compared to other growth areas, such as Cardinia (32\%) and Whittlesea (19\%), there is significantly less tree canopy coverage in Wyndham. 


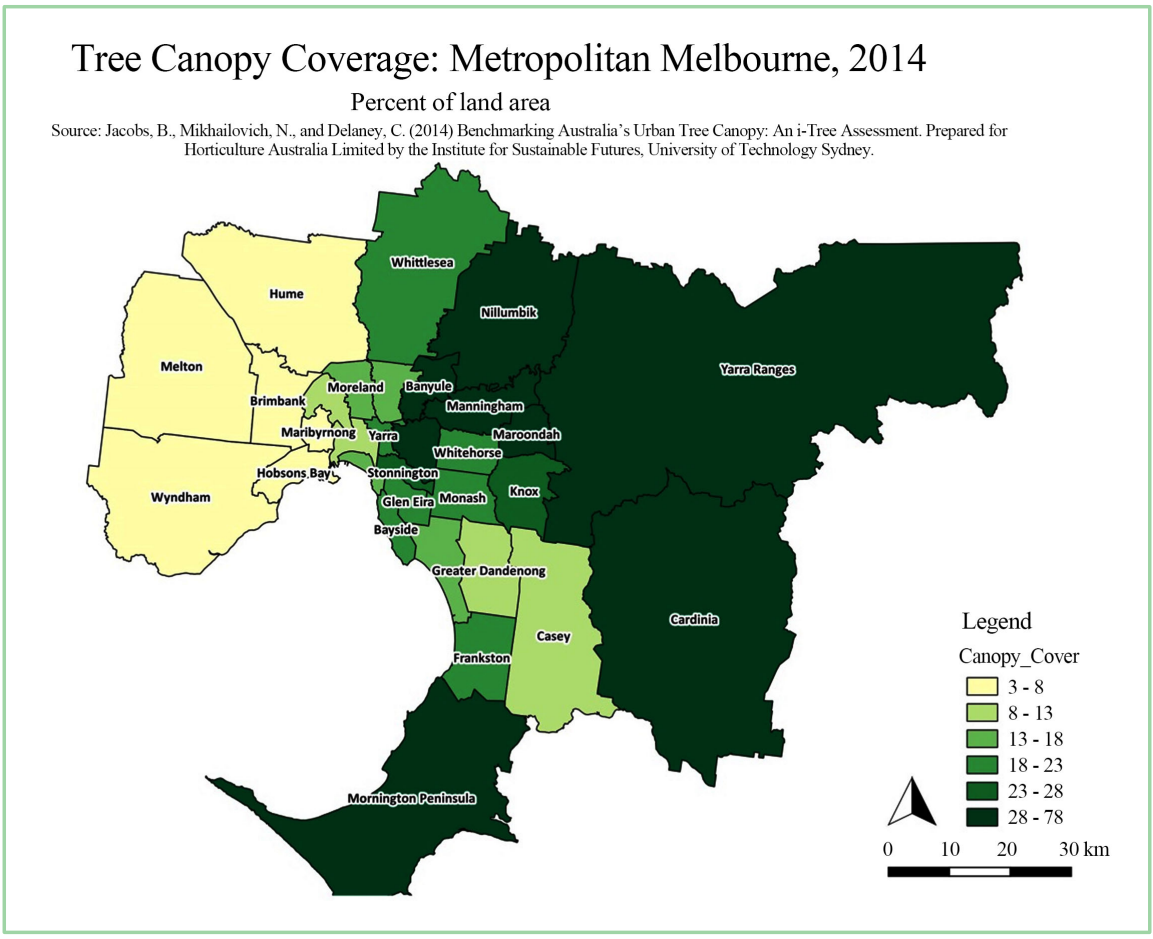

Figures 6. Tree Canopy Coverage: Metropolitan Melbourne, 2014.

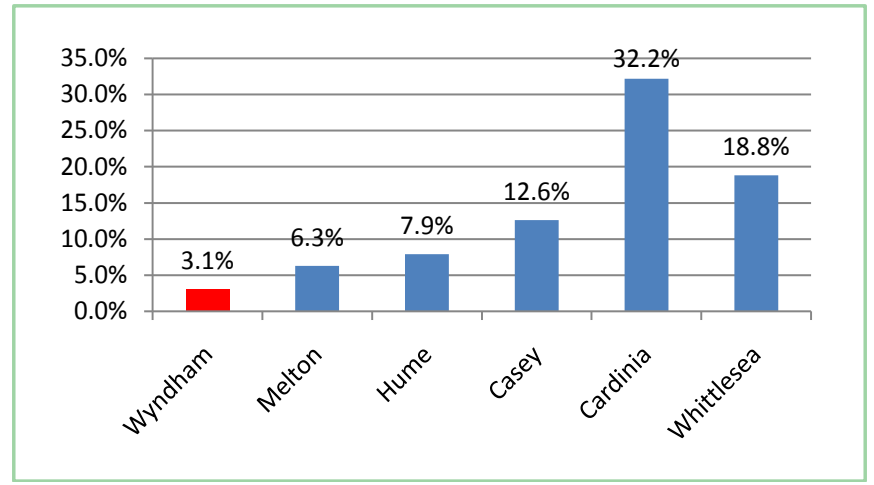

Figures 7. Percentage of LGA with Tree Canopy, 2015 [9].

The recommended planning scheme changes include a local planning policy addressing housing typology, and changes to zone schedules to ensure canopy trees are part of the development design, and that future residents have access to useable private open space. The elements of the proposed controls that promote an increase in tree canopy cover are summarized below.

\subsection{Local Planning Policy}

It is policy to achieve the provision of canopy trees that supports the delivery of preferred character in the established areas, softens the building form, and is proportionate in size to the scale of the development.

General Residential Zone Schedules:

- Preferred Character Objective for Neighbourhood Interface and Suburban 
Residential Housing Change Areas:

Improve landscape character by providing generous landscaping including canopy trees in front and rear setbacks to soften the visual impact of development.

- Preferred Character Objective for Suburban Residential Housing Change Areas:

Support a preferred neighbourhood character where landscaping is the prominent feature of development.

- Variation to Landscaping Standard B13 from ResCode (Clause 55.03-8) in proposed General Residential Zone Schedules 2 and 3:

Neighbourhood Interface Housing Change Area: Provide one canopy tree of minimum six metres mature height in the front and rear setbacks, with additional trees required for larger sites. Each tree provided within a clear unpaved area of $5 \mathrm{~m}$ by $5 \mathrm{~m}$, in addition to secluded private open space areas.

Suburban Residential Housing Change Area: Provide at least one canopy tree of minimum six metres mature height in the front and rear setbacks with additional trees required for larger sites. Each tree provided within a clear unpaved area of $5 \mathrm{~m}$ by $5 \mathrm{~m}$.

In addition, variations to the ResCode standards for secluded private open space and rear setbacks will increase the areas available for tree provision. Variations to ResCode standards to ensure the housing design allows for canopy trees can have a compounding impact on the design-they can affect site permeability, shade, building design and delivery of ground level open space.

\section{Conclusions}

The Urban Tree Canopy Coverage Project has shown a decline in urban tree canopy cover in the established areas of the municipality between 2009 and 2017, from an already low base. The decline was particularly severe within areas of high infill development activity.

The physical coverage of tree canopies over the land is a measure that can be used to assess community resilience to climate change. For example, a recent study on the urban heat island effect in Melbourne recommends that one of the most cost-efficient and effective climate change mitigation strategies is to ensure a minimum canopy cover of $30 \%$ within the municipality.

The data obtained in this project will support changes to the Whittlesea Planning Scheme to ensure that more canopy trees are delivered as part of new residential development. This is a key design element of the HDS and is an important adaptation strategy to assist community resilience to climate change.

We will use 2018 LiDAR data for 10 years comparation urban tree canopy analysis to better understand the structure, function and distribution of urban tree canopy within our public and private realm. To manage urban trees and develop canopy coverage benchmarks and policy aspirations requires an understanding of the density and spatial distribution of trees across the landscape. 


\section{Conflicts of Interest}

The authors declare no conflicts of interest regarding the publication of this paper.

\section{References}

[1] Tan, Z., Lau, K.K.-L. and Ng, E.J.E. (2016) Urban Tree Design Approaches for Mitigating Daytime Urban Heat Island Effects in a High-Density Urban Environment. Energy and Buildings, 114, 265-274. https://doi.org/10.1016/j.enbuild.2015.06.031

[2] City of Whittlesea (2019) Housing Diversity Strategy-Managing Housing Growth in the Established Suburbs.

https://www.whittlesea.vic.gov.au/building-planning-development/future-developm ent-plans/housing-diversity-strategy-managing-housing-growth-in-the-establishedsuburbs/

[3] Aguiar, A.C. (2012) Urban Heat Islands: Differentiating between the Benefits and Drawbacks of Using Native or Exotic Vegetation in Mitigating Climate. MA Thesis, University of Wollongong, Wollongong. https://pdfs.semanticscholar.org/f8da/7b58ecaf307a8d49a1d1381deecfbdc4d175.pdf

[4] Denham, T., Dodson, J., Palm, M., Whitzman, C., Hamilton, C., Kellet, J., Maginn, P. and Martinus, K. (2018) Transformational Infrastructure Projects in Australia's Fast Growing Outer Suburbs. Published by Centre for Urban Research (CUR) RMIT University.

https://findanexpert.unimelb.edu.au/scholarlywork/1327980-transformational-infra structure-projects-in-australia\%E2\%80\%99s-fast-growing-outer-suburbs

[5] Norton, B.A., Coutts, A.M., Livesly, S.J., Harris, R.J., Hunter, A.M. and Williams, N.S.G. (2015) Planning for Cooler Cities: A Framework to Prioritise Green Infrastructure to Mitigate High Temperatures in Urban Landscapes. Landscape and Urban Planning, 134, 127-138. https://doi.org/10.1016/j.landurbplan.2014.10.018

[6] Erell, E., Pearlmutter, D. and Williamson, T. (2012) Urban Microclimate: Designing the Spaces between Buildings. 1st Edition, Routledge, Taylor and Francis Group, London.

https://www.routledge.com/Urban-Microclimate-Designing-the-Spaces-Between-B uildings-1st-Edition/Erell-Pearlmutter-Williamson/p/book/9781138993983

[7] City of Melbourne (2012) Urban Forest Strategy-Making a Great City, Greener 2012-2032.

https://s3.ap-southeast-2.amazonaws.com/hdp.au.prod.app.com-participate.files/57 14/1273/7437/COM_SERVICE_PROD-_8591078-v1-Urban_Forest_Strategy_Docu ment_2014_Online.PDF

[8] City of Greater Geelong (2016) Area Profiles. https://profile.id.com.au/geelong

[9] Jacobs B.C., Mikhailovich N. and Delaney C. (2014) Benchmarking Australia’s Urban Tree Canopy: An I-Tree Assessment. Final Report, Prepared for Horticulture Australia Limited by the Institute for Sustainable Futures, University of Technology Sydney. https://www.researchgate.net/publication/265250961_Benchmarking_Australia\%27 s_Urban_Tree_Canopy_An_I-Tree_Assessment_Final_Report

[10] City of Whittlesea (2013) Housing Diversity Strategy 2013-2033. https://www.whittlesea.vic.gov.au/media/1829/housing-diversity-strategy-accessible .pdf

[11] SGS Economics and Planning (2018) Whittlesea 2040 Background Paper February 2018. 
https://www.whittlesea.vic.gov.au/media/3736/whittlesea-2040-background-researc h-paper.pdf

[12] City of Melbourne (2016) Resilient Melbourne: Viable, Sustainable, Liveable, Prosperous.

https://www.melbourne.vic.gov.au/SiteCollectionDocuments/resilient-melbourne-st rategy.pdf

[13] Daniel, C., Morrison, T.H. and Phinn, S. (2016) The Governance of Private Residential Lands in Cities and Spatial Effects on Tree Cover. Environmental Science \& Policy, 62, 79-89. https://doi.org/10.1016/j.envsci.2016.01.015 